292

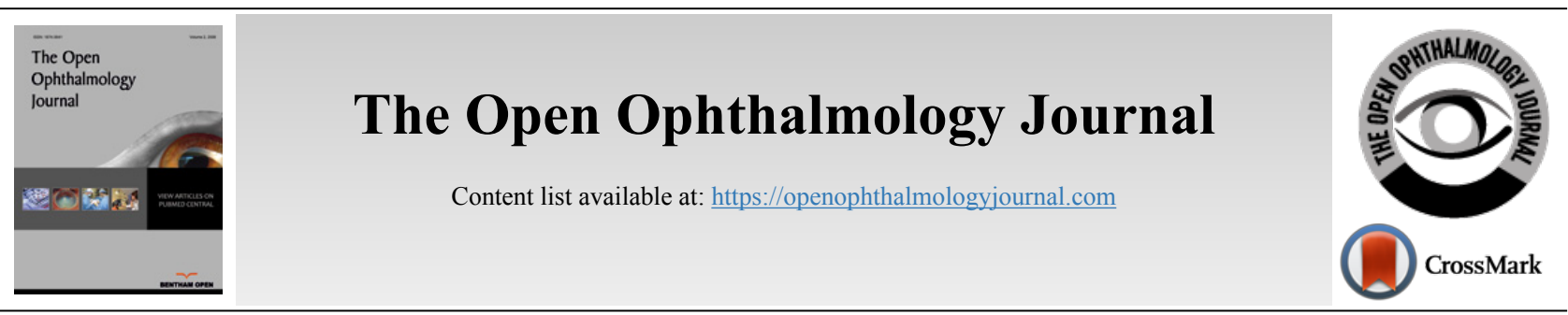

REVIEW ARTICLE

\title{
Autologous Retinal Transplant for Macular Hole
}

Sergio E. Hernández Da Mota ${ }^{1,2, *}$, Virgilio Morales-Cantón ${ }^{3}$, Sergio Rojas-Juárez ${ }^{4}$, Antonio López-Bolaños ${ }^{4}$, Abel Ramírez-Estudillo ${ }^{5}$ and Lisette Béjar Macouzet ${ }^{1,2}$

${ }^{\prime}$ Ophthalmology Department, Universidad Michoacana, Morelia, Mexico

${ }^{2}$ Retina Service, Clínica David, Unidad Oftalmológica BlvdGarcía de León 598-2, Colonia Nueva Chapultepec, CP 58280, Morelia, Michoacán, Mexico

${ }^{3}$ Retina Service, Hospital “Dr. Luis Sánchez Bulnes ”, Asociación para Evitar la Ceguera en México, IAP, UNAM, Mexico City, Mexico

${ }^{4}$ Retina Service, Instituto de Oftalmología, Fundación Conde de Valenciana, UNAM, Mexico City, Mexico

${ }^{5}$ Retina Service, Hospital Oftalmológico de Nuestra Señora de la Luz, UNAM, Mexico City, Mexico

\section{Abstract:}

We aim to review scientific literature concerning published studies on autologous retinal transplantation to treat macular hole patients. The following databases were searched: Medline and Medline Non-Indexed Items, Embase (1990-2020), Ovid Medline $(1990$ to November 2020), Embase (1990 to November 2020), Ovid Medline ${ }^{\circledR}$ and Epub Ahead of Print, in-Process and Web of Science (all years). Search keywords included "autologous", "retinal transplant", "autologous neurosensory retinal free flap" "transplantation", "macular hole", and "macular hole surgery". Eighteen case series and single case reports were reviewed.

Preoperative and final best-corrected visual acuity, microperimetry and multifocal electroretinogram findings, macular hole closure rate, preoperative and postoperative ellipsoid zone, and external limiting membrane defects were obtained and analyzed. Indications of autologous retinal transplantation for macular hole surgery included refractory macular holes, conventional techniques, and large macular holes. The number of cases included in the different case series ranged from 2 to 130 cases, and prior macular hole surgeries of the patients ranged from 0 to 3 . Overall, the published case series of autologous retinal transplants have reported a macular hole closure rate of 66.7 to $100 \%$, as well as a significant improvement in best-corrected visual acuity. The most frequently reported complications included considerable intraoperative bleeding and postoperative dislocation of the graft. The presence of functionality in the graft area has also been documented by microperimetry and multifocal electroretinogram.

In conclusion, the autologous retinal transplantation technique for macular hole patients has emerged as another surgical option, with a high macular hole closure rate and visual improvement.

Keywords: Autologous retinal transplant, Macular surgery, Macular hole, OCT, Microperimetry, Retinal graft.

\begin{tabular}{|l|l|l|l|}
\hline Article History & Received: June 9, 2021 & Revised: September 17, 2021 & Accepted: November 8, 2021
\end{tabular}

\section{INTRODUCTION}

Wendel and Kelly published the first series of cases with idiopathic MH presence successfully treated with vitrectomy [1].

Since MH surgery's original description, multiple variants to the original technique have been described [2 - 10]. Peeling the internal limiting membrane is one of the modifications to the original $\mathrm{MH}$ surgery technique that has increased the $\mathrm{MH}$ closure rate [2]. However, in up to $10 \%$ of the operated cases, the $\mathrm{MH}$ closure is not achieved with conventional surgery [5].

* Address correspondence to this author at the Retina Service, Clínica David, Unidad Oftalmológica Blvd. García de León 598-2, Colonia Nueva Chapultepec, CP 58280, Morelia, Michoacán, Mexico; Tel: +52 (443) 5280401;

E-mail: tolodamota@yahoo.com.mx.
In the last decade, several other techniques have been described for the treatment of MH hole patients. Some of these techniques use transplanted tissue either from the patient's eye or another donor, achieving the MH's closure through various mechanisms [3 - 10].

Autologous internal limiting membrane graft [3], autologous serum [4, 5], blood [6], lens capsule [7, 8], and amniotic membrane $[9,10]$ are some of the tissues used in $\mathrm{MH}$ surgery. One of the most recently described techniques is autologous retinal transplantation (ART). Grewal and Mahmoud described the original ART technique [11]. Since its introduction, several other ART case reports and case series have been published for $\mathrm{MH}$ [12 - 29] and other retinal diseases [30 - 32]. 
This review aims to describe some technical variants, the anatomical and functional results of the case series of ART for $\mathrm{MH}$ published to date. The following databases were searched: Embase (1990-2020), MEDLINE and MEDLINE NonIndexed Items, Ovid MEDLINE® (1990 to November 2020), Embase (1990 to November 2020), Ovid MEDLINE® and Epub Ahead of Print, in-Process and Web of Science (all years). Search keywords included "autologous", "retinal transplant", "autologous neurosensory retinal free flap" "transplantation", "macular hole", and "macular hole surgery". Inclusion criteria for the study/search included ART techniques descriptions for full-thickness $\mathrm{MH}, \mathrm{MH}$ with/without retinal detachment, naïve $\mathrm{MH}$ cases, and $\mathrm{MH}$ refractory cases. Nineteen case series and single case reports were reviewed, as they meet the study criteria; two of them were single case reports, and seventeen were case series. The articles included in this review were published between the years 2016 and 2020 .

\subsection{Surgical Techniques of Autologous Retinal Graft for Macular Hole}

In the first description of ART [11], a pars plana vitrectomy was performed using chandelier illumination. Subsequently, a laser barricade was applied around the area chosen for taking the autologous graft, adjacent and superior to the superotemporal vascular arcades, to avoid large retinal vessels to prevent significant bleeding once harvesting was performed.

Harvesting the graft can be accomplished, previously inducing a localized retinal detachment (RD) in the selected area for obtaining the graft, injecting saline solution into the subretinal space with a $41 \mathrm{Ga}$ needle [17], although many authors have described harvesting of the graft without inducing an RD [11 - 16, 20 - 24]. Inducing an RD may decrease the risk of traumatizing the choroid vessels with the scissors and subsequent bleeding [17]. In some cases, endodiathermy or laser were utilized to mark the retinal tissue and applied to the bleeding sites $[15,19]$.

The graft can be harvested using $23 \mathrm{Ga}$ or $25 \mathrm{Ga}$ vertical scissors, holding it by one of its edges with $23 \mathrm{Ga}$ or $25 \mathrm{Ga}$ forceps. Once harvested, the graft is displaced to the hole site, using a $23 \mathrm{Ga}$ or $25 \mathrm{Ga}$ silicone tipped cannula and stabilizing it with perfluorocarbon fluids (PFs). Graft dislocation is prevented by lowering the intraocular pressure setting to reduce turbulence in the fluid stream [15, 19, 21 - 29]. Afterward, a PFs-silicone oil exchange is carried out. A prone position is prescribed to the patient for one week, and the silicone oil was removed after approximately four months [19].

Some variants of the original technique have been published [12 - 28]. The site where the graft is harvested depends on the surgeon's preference. It has been obtained outside the vascular arcades from the superior, superotemporal, temporal, inferotemporal, inferior, inferonasal, or nasal areas $[11,13,15,19]$. A bimanual technique is recommended to harvest the graft, and it has been performed on the retina immediately internal to the area where the laser barricade was applied.
The autologous graft size should be approximately 1.5 to 2 times larger than the MH's diameter [13, 15, 19]. It has been positioned above or below the MH edges [17, 19]. Tamponades used have included $\mathrm{PFs}, \mathrm{C}_{3} \mathrm{~F}_{8}$ gas, silicone oil, $\mathrm{SF}_{6}$, and air [12 28].

\subsection{Anatomical Outcomes}

The publications to date on ART are isolated case reports or case series. The most extensive case series have been published by Moysidis et al. [19].

Table 1 shows the baseline characteristics of the cases included in the published case series. Most MH cases had a minimum diameter larger than $500 \mu \mathrm{m}$ and at least one previously failed vitrectomy. Authors have reported ART in first-time operations in those cases with chronic, large macular holes. One of the patients had retinal detachment related to a large macular hole. Common indications to perform ART were those cases that had undergone several surgeries.

Table 1. Autologous retinal transplant in MH. Baseline characteristics and postoperative follow-up of the different case series.

\begin{tabular}{|l|c|c|c|c|}
\hline Publication & $\begin{array}{l}\text { Number } \\
\text { of Cases }\end{array}$ & $\begin{array}{l}\text { Prior } \\
\text { Surgeries }\end{array}$ & $\begin{array}{l}\text { Follow-up } \\
\text { Time } \\
\text { (Months) }\end{array}$ & $\begin{array}{l}\text { MH Minimum } \\
\text { Diameter } \\
(\boldsymbol{\mu m} \pm \text { SD) }\end{array}$ \\
\hline Ding et al. & 5 & 1 & 6 & - \\
\hline Wu et al. & 6 & $2.3 \pm 0.5$ & $25.3 \pm 15.6$ & $538 \pm 184.9$ \\
\hline Thomas et al. & 2 & $2-3$ & $3-12$ & - \\
\hline Tanaka et al. & 7 & 0 & 16 & 643 \\
\hline Grewal et al. & 41 & $1-3$ & $11.1 \pm 7.7$ & $825 \pm 422.5$ \\
\hline Chang et al. & 10 & $2-3$ & 12 & $1404.2 \pm 562.9$ \\
\hline Moysidis et al. & 130 & $1.7 \pm 0.2$ & $8.6 \pm 1$ & $837 \pm 34$ \\
\hline Li et al. & 10 & $2-3$ & $\geq 3$ & $1192.6 \pm 467.5$ \\
\hline Yamada et al. & 4 & $1-2$ & 6 & $>400$ \\
\hline Lumi $e t$ al. & 4 & $0->1$ & $13-23$ & 828 \\
\hline Tabandeh et al. & 2 & $>1$ & $3-6$ & $>2000$ \\
\hline Rojas et al. & 13 & $>1$ & 12 & $964.4 \pm 709.77$ \\
\hline
\end{tabular}

MH: Macular Hole SD: Standard Deviation.

Table 2 shows the anatomical results of the published series. Closure rates range from $66.7 \%$ to $100 \%$. Grewal et al. [15] reported $\mathrm{MH}$ closure in 36 of 41 included cases in their series. Moysidis et al. [19] reported an $89 \%$ anatomical closure rate in a series of 130 cases.

Several findings have been described in OCT analysis during follow-up in patients that have undergone ART surgery. Hyperreflectivity of the transplanted graft internal layers has been observed in the first weeks after surgery. It decreases after a few weeks $[17,19,22]$. After several months, progressive alignment of neurosensory layers of the graft and host retina has been described.

Another finding observed by OCT imaging is vertical, hyperreflective, and irregular lines that represent bridging or transitional tissue between the transplanted graft and the host retinal tissue and the presence of a wooly-like, hyperreflective tissue in the surface of the graft that tends to decrease during follow-up [17]. 
Table 2. MH closure rate and decrease of the EZ and ELM defects.

\begin{tabular}{|c|c|c|c|c|c|c|c|}
\hline Publication & Percentage of Cases with MH Closure & $\begin{array}{c}\text { Baseline } \\
\text { EZ Defect } \\
(\mu \mathrm{m} \pm \mathrm{SD})\end{array}$ & $\begin{array}{c}\text { Final } \\
\text { EZ Defect } \\
(\mu \mathrm{m} \pm \mathrm{SD})\end{array}$ & $p$ & \begin{tabular}{|c|} 
Baseline \\
ELM Defect \\
$(\mu \mathrm{m} \pm \mathrm{SD})$
\end{tabular} & $\begin{array}{c}\text { Final } \\
\text { ELM Defect } \\
(\mu \mathrm{m} \pm \mathrm{SD})\end{array}$ & $p$ \\
\hline Ding et al. & 100 & _- & _- & _- & _- & _- & _- \\
\hline Wu et al. & 66.7 & _ & - & _- & _- & - & - \\
\hline Thomas et al. & 100 & - & - & - & - & - & - \\
\hline Tanaka et al. & 100 & $1089 \pm 403.8$ & $921 \pm 129.1$ & 0.09 & - & - & - \\
\hline Grewal et al. & 87.8 & $1777.3 \pm 513.8$ & $1370 \pm 556.9$ & 0.007 & $1681.5 \pm 429$ & $1408.5 \pm 571.2$ & 0.017 \\
\hline Chang et al. & 90 & _- & $60 \% *$ & 0.003 & - & _- & - \\
\hline Moysidis et al. & 89 & _ & $50 \% *$ & _ & _ & $54 \%^{\dagger}$ & _ \\
\hline Li et al. & 80 & _- & _- & _- & $\ldots$ & _ & _- \\
\hline Yamada et al. & 100 & - & _ & _ & _ & _ & - \\
\hline Lumi et al. & 100 & _- & _- & _- & $\ldots$ & _- & _- \\
\hline Tabandeh et al. & 100 & _- & $\ldots$ & - & _ & _ & - \\
\hline Rojas et al. & 77 & $1277.4 \pm 538.78$ & $478.5 \pm 589.5^{\ddagger}$ & - & - & - & - \\
\hline
\end{tabular}

MH: Macular Hole SD: Standard Deviation EZ: Ellipsoid Zone ELM: External Limiting Membrane * percentage of cases with continuity restoration of the EZ ${ }^{\dagger}$ percentage of cases with continuity restoration of the $\mathrm{ELM}^{\ddagger}$ Six patients showed full recovery of the myoid/ellipsoid layers at the end of the follow-up. The remaining four showed a reduction of $44.9 \%$ of the defect.

The OCT analysis showed complete structural integration of the retinal transplant into the adjacent retina in some cases. In other cases, the transplant was integrated into the retina, but not all layers could be recognized [15, 17, 19, 22].

Grewal et al. [15] reported a significant decrease in the External Limiting Membrane (ELM) and Ellipsoid Zone (EZ) and defects at the end of follow-up compared to baseline ( $\mathrm{p}<$ $0.05)$.

The OCT analysis showed complete structural integration of the retinal transplant into the adjacent retina in some cases. In other cases, the transplant was integrated into the retina, but not all layers could be recognized.

Vascularization and reperfusion of the retinal graft were observed within six weeks of transplantation by OCT- angiography, as reported by Tabandeh et al. [28].

Grewal et al. [15] reported a significant decrease in the External Limiting Membrane (ELM) and Ellipsoid Zone (EZ) and defects at the end of follow-up compared to baseline $(\mathrm{p}<$ $0.05)$.

\subsection{Functional Outcomes}

Best-Corrected Visual Acuity (BCVA) improved in at least three lines in $43 \%$ and at least five lines in $29 \%$ of the cases, as reported by Moysidis et al. [19]. All series showed a significant improvement at the end of follow-up compared with baseline preoperative BCVA (Table 3). Four of the series have documented sensitivity by microperimetry with improvement in fixation [18, 19, 22, 23].

Table 3. Preoperative and postoperative BCVA. Microperimetry and mfERG findings.

\begin{tabular}{|c|c|c|c|c|c|}
\hline Publication & Preoperative BCVA* & Final BCVA & $p$ & Microperimetry & mfERG \\
\hline Ding et al. & $2.4 \pm 0.6$ & $1.46 \pm 0.5$ & $<0.05$ & - & _ \\
\hline Wu et al. & 1.30 & 1.10 & & 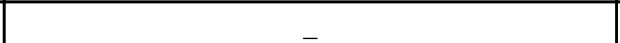 & - \\
\hline Thomas et al. & $1.30-2.00 * *$ & $0.90-1.3$ & - & _- & - \\
\hline Tanaka et al. & 1.00 & 0.70 & 0.001 & Recordable sensitivity in 5 cases in the graft's zone & _- \\
\hline Grewal et al. & $1.11 \pm 0.6$ & $1.03 \pm 0.5$ & 0.005 & _- & - \\
\hline Chang et al. & $1.65 \pm 0.43$ & $0.87 \pm 0.50$ & 0.001 & _ & _ \\
\hline Moysidis et al. & 1.30 & 0.90 & $<0.001$ & $\begin{array}{l}\text { Increase in fixation. } \\
6.7 \pm 1.9 \mathrm{~dB} \text { sensitivity }\end{array}$ & Recordable b wave amplitude ${ }^{\S \S}$ \\
\hline Li et al. & $2.01 \pm 0.3$ & $1.32 \pm 0.3$ & 0.000 & Non-recordable sensitivity in the graft's zone ${ }^{\S}$ & _ \\
\hline Yamada et al. & $1.88 \pm 0.47$ & $1.17 \pm 0.21$ & - & $\begin{array}{l}12^{\circ} \text { fovea area showed retinal sensitivity of fixation } \\
\text { view point at final visit }\end{array}$ & - \\
\hline Lumi et al. & 3.87 & 0.62 & - & $\begin{array}{l}\text { Median sensitivity in the area of the transplant of } 4 \mathrm{~dB} \\
\text { (range } 1.8-12.4 \mathrm{~dB})\end{array}$ & $\begin{array}{l}\text { mfERG showed the abnormal } \\
\text { function of the central ring and } \\
\text { normal function of the second } \\
\text { ring in } 3 \text { cases }\end{array}$ \\
\hline Tabandeh et al. & $2.00-1.00^{* *}$ & $1.00-0.88$ & _ & _- & - \\
\hline Rojas et al. & $0.92 \pm 0.28$ & $0.75 \pm 0.29$ & 0.034 & - & - \\
\hline
\end{tabular}

BCVA: Best-Corrected Visual Acuity mfERG: multifocal electroretinogram * LogMAR (logarithm of the minimum angle of resolution) units were used to describe BCVA ** Snellen notation was converted to LogMAR units ${ }^{\ddagger}$ Average sensitivity decibels in 12 cases ${ }^{\S}$ Sensitivity improvement in the autologous graft’s adjacent zone ${ }^{\S \S}$ mfERG performed in 3 patients. Recordable b wave amplitude in the graft's zone. 
Microperimetry findings showed that spatially, the functional regions were located in the transplants' peripheral regions while no function was detected in the region corresponding to the foveal center. Fixation was relatively unstable and eccentric in all patients, located either in the nasal or nasal-superior perifoveal region or near the transplant border [17].

Tanaka et al. [18] reported that five of the seven eyes included in their series showed a positive response to light stimuli in the graft retinas when examined with microperimetry. In contrast, the two eyes with unchanged visual acuity had a negative response to light in the graft.

Moysidis et al. [19] reported a recordable b wave in the autologous graft's area while Lumi et al. [22] reported abnormal function of the central ring and normal function of the second ring in three cases by multifocal electroretinogram (mfERG).

The reconstitution of the EZ on optical coherence tomography (OCT) was associated with a better final visual outcome $(\mathrm{p}=0.02)[14]$.

\subsection{Complications}

The largest case series of ART published by Moysidis et al. [19] reported some complications that are shown in Table 4.

Table 4. Complications.

\begin{tabular}{|c|c|}
\hline Complication & Percentage (n) \\
\hline \multicolumn{2}{|l|}{ Intraoperative complications } \\
\hline Graft dislocation & $3.8 \%(\mathrm{n}=5)$ \\
\hline Undersized graft & $2.7 \%(\mathrm{n}=2)$ \\
\hline Damage to the RPE & $0.8 \%(\mathrm{n}=1)$ \\
\hline \multicolumn{2}{|l|}{ Postoperative complications* } \\
\hline Retinal detachment & $3.8 \%(\mathrm{n}=5)$ \\
\hline Endophthalmitis & $0.8 \%(\mathrm{n}=1)$ \\
\hline Damage to the RPE & $2.7 \%(\mathrm{n}=2)$ \\
\hline Subretinal or vitreous hemorrhage & $6.6 \%(n=5)$ \\
\hline
\end{tabular}

Grewal et al. [15] reported an RD in one case and a vitreous hemorrhage as major postoperative complications in their series. Tanaka et al. [18] reported in one eye that the harvested retina seemed to have been incorrectly transplanted upside down with unchanged visual acuity in the follow-up period. Macular edema occurred in another eye three months after transplantation that was successfully treated with a steroid injection. Rojas et al. [29] reported during the follow-up that one patient developed mild posterior proliferative vitreoretinopathy, and another demonstrated a macular epiretinal membrane. In other series, no significant intraoperative and postoperative complications were reported $[12,14,16,21-23]$.

\section{DISCUSSION}

ART is a novel technique that has shown its usefulness in treating both primary and refractory $\mathrm{MH}$ cases.

Nonetheless, several issues regarding the best tamponade and techniques are still debated [11 - 29].

Regarding tamponade use, different tamponade types have been used to keep the graft in place to prevent its dislocation. PFs have been used for a few days as a tamponade. They probably also have the advantage of increasing oxygen diffusion to the ART, contributing to its viability, thus favorably impacting functional outcomes postoperatively [15, 19]. Nonetheless, silicone oil or PFs as tamponades have the main disadvantage of often requiring a second surgery to remove them [19]. A second surgical procedure may entail additional risks both at an ocular and systemic level for the patient.

Some authors have used gas or air to overcome the disadvantage of performing a second procedure using PFs or silicone oil [15, 19]. Hernandez-Da Mota et al. [17] described a technique using only air as a tamponade, placing the transplanted tissue below the MH's edges. The graft did not dislocate, fully integrating with the adjacent retina after a few months. Moreover, Lumi et al. [22] reported that a better recovery of the ellipsoid zone was seen in OCT in subretinally positioned graft cases.

Another unsolved issue is defining which ART technique could be less traumatic and has greater anatomic and functional success. In relation to performing the less traumatic surgical procedure, one of the crucial steps in ART is harvesting the graft. It requires delimiting the graft's harvest area first with a laser barricade and circumferentially cutting the graft. It can be harvested, previously inducing a localized RD in the selected area for obtaining the graft, injecting saline solution into the subretinal space with a $41 \mathrm{Ga}$ needle. It is also possible to harvest the graft without prior induction of an $\operatorname{RD}[15,19]$.

In addition, harvesting the graft without previously inducing an $\mathrm{RD}$ could be less traumatic for the photoreceptors; nonetheless, it carries the potential risk of traumatizing the choroidal vessels with the scissors, causing significant bleeding, and thus complicating the surgery [19]. PFs have also been used to stabilize the graft once it has been harvested, moving it over the retinal surface to the hole with another instrument, generally, a silicone-tipped cannula $[11,15]$.

Displacing the graft under PFs may rub the graft's inner face against the retinal surface, resulting in potential damage and loss of photoreceptors. Moreover, it could have a harmful impact on the final visual outcome in these patients.

Bimanual techniques have been used to overcome this disadvantage $[11,15,19]$. They do not require the displacement of the graft under $\mathrm{PFs}$, thus avoiding photoreceptors' damage and using air or $\mathrm{SF}_{6}$ gas as tamponades [17]. With these tamponades, it has been observed that the graft remained in the $\mathrm{MH}$ site without dislocating.

Interestingly, several postoperative changes have been documented by OCT [11 - 29]. First, hyperreflectivity of the internal retinal layers suggests edema, and it has been reported in the first weeks after ART has been performed [15, 17]. Likely, the edema present in the transplanted graft in the first postoperative days and weeks contributes to the graft pressing against the MH's edges, closing it hermetically. Together with the RPE pump's action, the hermetic closure would probably 
keep the graft between the edges of the hole without dislocating, thus allowing its eventual integration with the receptor tissue.

The internal retinal layers hyperreflectivity, observed in the first postoperative weeks, may occur due to the arterial circulation interruption of the superficial and deep retinal plexuses after the graft is harvested [17]. Conversely, the transplanted graft's external retinal layers do not show this hyperreflectivity, possibly because when placed in the $\mathrm{MH}$ area, they begin to receive blood supply from the choriocapillaris immediately [17]. Furthermore, retinal vascular plexuses at the MH edges have shown the structural formation of new loops from the perifoveal capillary network that project towards the transplanted graft by OCTangiography during follow-up [28].

This reperfusion process likely involves localized upregulation of angiogenic pathways by an ischemic retinal graft [28]. Authors have hypothesized that a large ischemic area retinal graft produces enough angiogenic stimulus to initiate angiogenesis, resulting in neovascularization and anastomosis between the superficial and deep vascular plexuses, reperfusing the graft. As the retinal graft reperfuses, ischemic signaling diminishes, downregulates angiogenic drive, and decreases further angiogenesis [28].

Another OCT finding that has been observed is the preservation of the EZ and ELM continuity, which may be a potential imaging biomarker of the viability of the transplanted photoreceptors and visual improvement $[11,15,19]$.

In addition, the integration of the autologous graft into the recipient tissue has also been documented in different publications using OCT imaging, and it is noteworthy that the transplanted tissue undergoes structural changes until the integration into the recipient retina is completed $[11,17,15$, 19, 22].

Functional outcomes include, in addition to the improvement in BCVA in the different published series, fixation and sensitivity documented by microperimetry and $a b$ wave recordable by mfERG in the graft area [18, 19, 22, 23]. Nonetheless, Lumi et al. [22] reported that the functional regions were located in the transplants' peripheral areas. Simultaneously, no function was detected by microperimetry in the region corresponding to the foveal center. As shown by mfERG and microperimetry, functional integration suggests some gradual functional integration of the transplants' outer regions [22].

How the transplanted retinal tissue's functionality is achieved and maintained in the postoperative period is the subject of speculation. Several hypotheses have been proposed to explain the graft's integration and possible neuronal reconnection with the retinal receptor tissue to achieve and maintain the transplanted graft functionality [33 - 41].

One hypothesis proposes the formation of new synapses in the bipolar cells of the recipient tissue. These newly formed synapses would reconnect with the outer plexiform layers and the transplanted tissue's photoreceptors' terminal plates. Peng et al. $[33,34]$ documented this process in an animal model of retinitis pigmentosa $[\mathrm{RP}]$. They described that bipolar cells' synapsis reconnected with the cones in the rods' absence. This process is known as ectopic synaptogenesis [33 - 41].

Furthermore, Lorach et al. [41] transplanted retinal tissue from healthy rats into the subretinal space of rats with RP. They were able to document, using immunohistochemistry and confocal microscopy, the formation of synaptic outgrowths of the bipolar cells in the retinal receptor tissue. The colocalization of the dendrites with the synaptic ribbons present in the synaptic endplates of the transplanted tissue's photoreceptors in the external plexiform layer was observed.

Noticeably, ectopic synaptogenesis has not been described in humans to the best of our knowledge. Probably, imaging techniques, such as adaptive optics to visualize in vivo details at the retinal tissue's cellular level, could be performed and may contribute to elucidating how ART integrates into the receptor's retina [19].

Lastly, all the published series' limitations include the lack of a control group to compare the ART technique, their retrospective nature, and the variability between the different techniques [11 - 29]. Designing prospective, comparative, and multicentric studies that include variables obtained with retinal autofluorescence, mfERG, microperimetry, and adaptive optics is warranted. Moreover, post-mortem histopathology in animal models may explain how the transplanted graft's retinal layers align and integrate with the recipient's retinal tissue [19].

\section{CONCLUSION}

The ART technique for the treatment of $\mathrm{MH}$ is a new technique that effectively induces a high percentage of MH's closure, especially those refractory to conventional surgery, and has a low incidence of complications [11 - 29].

Significant visual improvement was documented in the published case series [11 - 29]. Furthermore, evidence of the retinal graft functionality by microperimetry and mfERG has been described. However, there is still a lack of knowledge about the mechanisms involved in the graft's functional improvement and integration with the recipient retina in humans [19].

The ART technique is an additional surgical alternative to those previously described for some MH cases, which expands the treatment options and offers functional improvement in patients with this macular disease.

\section{LIST OF ABBREVIATIONS}

$$
\begin{array}{ll}
\text { RD } & =\text { Retinal Detachment } \\
\text { ART } & =\text { Autologous Retinal Transplantation } \\
\text { MH } & =\text { Macular Hole } \\
\text { SD } & =\text { Standard Deviation } \\
\text { EZ } & =\text { Ellipsoid Zone } \\
\text { ELM } & =\text { External Limiting Membrane } \\
\text { OCT } & =\text { Optical Coherence Tomography } \\
\text { RPE } & =\text { Retinal Pigment Epithelium } \\
\text { PF } & =\text { Perfluorocarbon Fluids } \\
\text { BCVA } & =\text { Best-Corrected Visual Acuity }
\end{array}
$$


mfERG = Multifocal Electroretinogram

LogMAR $=$ Logarithm of the Minimum Angle of Resolution.

\section{CONSENT FOR PUBLICATION}

Not applicable.

\section{FUNDING}

None.

\section{CONFLICT OF INTEREST}

The authors declare no conflict of interest, financial or otherwise

\section{ACKNOWLEDGEMENTS}

The authors acknowledge the administrative and technical staff of Clinica David in Morelia, Mexico, for collecting the clinical data and images for this publication.

\section{REFERENCES}

[1] Kelly NE, Wendel RT. Vitreous surgery for idiopathic macular holes. Results of a pilot study. Arch Ophthalmol 1991; 109(5): 654-9. [http://dx.doi.org/10.1001/archopht.1991.01080050068031] [PMID: 2025167]

[2] Eckardt C, Eckardt U, Groos S, Luciano L, Reale E. Removal of the internal limiting membrane in macular holes. Clinical and morphological findings. Ophthalmologe 1997; 94(8): 545-51. [http://dx.doi.org/10.1007/s003470050156] [PMID: 9376691]

[3] Michalewska Z, Michalewski J, Adelman RA, Nawrocki J. Inverted internal limiting membrane flap technique for large macular holes. Ophthalmology 2010; 117(10): 2018-25. [http://dx.doi.org/10.1016/j.ophtha.2010.02.011] [PMID: 20541263]

[4] Kutsuna M, Kusaka S, Sakagami K, Ohashi Y. Treatment of fullthickness macular holes with autologous serum. Nippon Ganka Gakkai Zasshi 1997; 101(5): 407-12.

[http://dx.doi.org/10.1016/S0021-5155(97)90188-X] [PMID: 9170846]

[5] Dimopoulos S, William A, Voykov B, Ziemssen F, Bartz-Schmidt $\mathrm{KU}$, Spitzer MS. Anatomical and visual outcomes of autologous thrombocyte serum concentrate in the treatment of persistent fullthickness idiopathic macular hole after ILM peeling with brilliant blue $\mathrm{G}$ and membrane blue dual. Acta Ophthalmol 2017; 95(5): e429-30. [http://dx.doi.org/10.1111/aos.12971] [PMID: 26893064]

[6] Lai CC, Chen YP, Wang NK, et al. Vitrectomy with internal limiting membrane repositioning and autologous blood for macular hole retinal detachment in highly myopic eyes. Ophthalmology 2015; 122(9): 1889-98.

[http://dx.doi.org/10.1016/j.ophtha.2015.05.040] [PMID: 26143541]

[7] Chen SN, Yang CM. Lens capsular flap transplantation in the management of refractory macular hole from multiple etiologies. Retina 2016; 36(1): 163-70.

[http://dx.doi.org/10.1097/IAE.0000000000000674] [PMID: 26200509]

[8] Yepez JB, Murati FA, De Yepez J, Petitto M, Arevalo JF. Anterior lens capsule in the management of chronic full-thickness mauclar hole. Retin Cases Brief Rep 2018; 12(4): 286-90.

[http://dx.doi.org/10.1097/ICB.0000000000000513] [PMID: 28033231]

[9] Caporossi T, Pacini B, De Angelis L, Rizzo S. Amniotic membrane plug to promote chronicpost-traumatic macular hole closure. Ophthalmic Surg Lasers Imaging Retina 2019; 51(1): 50-2. [http://dx.doi.org/10.3928/23258160-20191211-07] [PMID: 31935303]

[10] Caporossi T, Pacini B, Bacherini D, Barca F, Faraldi F, Rizzo S. Human amniotic membrane plug to promote failed macular hole closure. Sci Rep 2020; 10(1): 18264.

[http://dx.doi.org/10.1038/s41598-020-75292-2] [PMID: 33106542]

[11] Grewal DS, Mahmoud TH. Autologous neurosensory retinal free flap for closure of refractory myopic macular holes. JAMA Ophthalmol 2016; 134(2): 229-30. [http://dx.doi.org/10.1001/jamaophthalmol.2015.5237]

[PMID: 26720054]

[12] Wu AL, Chuang LH, Wang NK, et al. Refractory macular hole repaired by autologous retinal graft and blood clot. BMC Ophthalmol 2018; 18(1): 213 .

[http://dx.doi.org/10.1186/s12886-018-0898-8] [PMID: 30157808]

[13] Chang YC, Liu PK, Kao TE, Chen KJ, Chen YH, Chiu WJ. Management of refractory large macular hole with autologous neurosensory retinal free flap transplantation. Retina 2020; 40(11): 2134-9.

[http://dx.doi.org/10.1097/IAE.0000000000002734]

[PMID: 31876885]

[14] Ding C, Li S, Zeng J. Autologous neurosensory retinal transplantation for unclosed and large macular holes. Ophthalmic Res 2019; 61(2): 88-93.

[http://dx.doi.org/10.1159/000487952] [PMID: 29788031]

[15] Grewal DS, Charles S, Parolini B, Kadonosono K, Mahmoud TH. Autologous retinal transplant for refractory macular holes: Multicenter international collaborative study group. Ophthalmology 2019; 126(10): 1399-408.

[http://dx.doi.org/10.1016/j.ophtha.2019.01.027] [PMID: 30711606]

[16] Li Y, Li Z, Xu C, Liu Y, Kang X, Wu J. Autologous neurosensory retinal transplantation for recurrent macular hole retinal detachment in highly myopic eyes. Acta Ophthalmol 2020; 98(8): e983-90. [http://dx.doi.org/10.1111/aos.14442] [PMID: 32323479]

[17] Hernández-Da Mota SE, Ramírez-Estudillo A, Morales-Cantón V. Optical coherence tomography findings in a case of macular hole treated with an autologous retinal transplant. Arch Soc Esp Oftalmol 2020; S0365-6691(20): 30204-5.

[18] Tanaka S, Inoue M, Inoue T, et al. Autologous retinal transplantation as a primary treatment for large chronic macular holes. Retina 2020; 40(10): 1938-45.

[http://dx.doi.org/10.1097/IAE.0000000000002693] [PMID: 31800464]

[19] Moysidis SN, Koulisis N, Adrean SD, Charles S, Chetty N, Chhablani JK. Autologous retinal transplantation for primary and refractory macular holes, and macular hole retinal detachments: The global consortium. Ophthalmology 2020; S0161-6420(20): 30979-9.

[http://dx.doi.org/10.1016/j.ophtha.2020.10.007]

20] Lazić R, Drača N, Cerović V, Katić D, Mladenovski S, Gabrić N. Autologous neurosensory retinal free flap treatment for a large macular hole. Ophthalmic Surg Lasers Imaging Retina 2018; 49(9): e89-92.

[http://dx.doi.org/10.3928/23258160-20180907-13]

[PMID: 30222825]

[21] De Giacinto C, D’Aloisio R, Cirigliano G, Pastore MR, Tognetto D. Autologous neurosensory retinal free patch transplantation for persistent full-thickness macular hole. Int Ophthalmol 2019; 39(5): 1147-50.

[http://dx.doi.org/10.1007/s10792-018-0904-4] [PMID: 29589232]

[22] Lumi X, Pajic SP, Sustar M, Fakin A, Hawlina M. Autologous neurosensory free-flap retinal transplantation for refractory chronic macular hole-outcomes evaluated by OCT, microperimetry, and multifocal electroretinography. Graefes Arch Clin Exp Ophthalmol 2021; 259(6): 1443-53.

[http://dx.doi.org/10.1007/s00417-020-04981-5] [PMID: 33090282]

[23] Yamada K, Maeno T, Kusaka S, Arroyo JG, Yamada M. Recalcitrant macular hole closure by autologous retinal transplant using the peripheral retina. Clin Ophthalmol 2020; 14: 2301-6. [http://dx.doi.org/10.2147/OPTH.S236592] [PMID: 32848358]

[24] Chang YC, Liu PK, Kao TE, et al. Management of refractory large macular hole with autologous neurosensory retinal free flap transplantation. Retina 2020; 40(11): 2134-9.

[http://dx.doi.org/10.1097/IAE.0000000000002734]

[PMID: 31876885]

[25] Takeuchi J, Kataoka K, Shimizu H, Tomita R, Kominami T, Ushida H. Intra and postoperative monitoring of autologous neurosensory retinal flap transplantation for refractory macular hole associated with high myopia. Retina 2020.

[http://dx.doi.org/10.1097/IAE.0000000000003000]

[PMID: 33079787]

[26] Thomas AS, Mahmoud TH. Subretinal transplantation of an autologous retinal free flap for chronic retinal detachment with proliferative vitreoretinopathy with or without macular hole. Retina 2018; 38(Suppl. 1): S121-4.

[http://dx.doi.org/10.1097/IAE.0000000000002026] [PMID: 29293208] 
[27] Liu PK, Chang YC, Wu WC. Management of refractory macular hole with blood and gas-assisted autologous neurosensory retinal free flap transplantation: A case report. BMC Ophthalmol 2018; 18(1): 230. [http://dx.doi.org/10.1186/s12886-018-0909-9] [PMID: 30176829]

[28] Tabandeh $\mathrm{H}$. Vascularization and reperfusion of autologous retinal transplant for giant macular holes. JAMA Ophthalmol 2020; 138(3): 305-9.

[http://dx.doi.org/10.1001/jamaophthalmol.2019.5733]

[PMID: 31944234]

[29] Rojas-Juárez S, Cisneros-Cortés J, Ramirez-Estudillo A, VelezMontoya R. Autologous full-thickness retinal transplant for refractory large macular holes. Int J Retina Vitreous 2020; 6(1): 60. [http://dx.doi.org/10.1186/s40942-020-00266-5] [PMID: 33292851]

[30] Caramoy A, Fauser S, Kirchhof B. Retinal stimuli can be restored after autologous transplant of retinal pigment epithelium and choroid in pigment epithelium tears. Acta Ophthalmol 2011; 89(6): e490-5.

[http://dx.doi.org/10.1111/j.1755-3768.2011.02143.x] [PMID: 21410906]

[31] Temmerman IM, Mahmoud TH, Veckeneer MAH. Autologous neurosensory retinal transplant to treat refractory serous retinal detachment secondary tooptic disc coloboma. Retin Cases Brief Rep 2020.

[http://dx.doi.org/10.1097/ICB.0000000000001031]

[PMID: 32568957]

[32] Parolini B, Grewal DS, Pinackatt SJ, et al. Combined autologous transplantation of neurosensory retina, retinal pigment epithelium, and choroid free grafts. Retina 2018; 1(Suppl 1): S12-22. [http://dx.doi.org/10.1097/IAE.0000000000001914]

[33] Peng YW, Hao Y, Petters RM, Wong F. Ectopic synaptogenesis in the mammalian retina caused by rod photoreceptor-specific mutations. Nat Neurosci 2000; 3(11): 1121-7.

[http://dx.doi.org/10.1038/80639] [PMID: 11036269]

[34] Peng YW, Senda T, Hao Y, Matsuno K, Wong F. Ectopic synaptogenesis during retinal degeneration in the royal college of surgeons rat. Neuroscience 2003; 119(3): 813-20. [http://dx.doi.org/10.1016/S0306-4522(03)00153-2]

[PMID: 12809702

[35] Lewis GP, Linberg KA, Fisher SK. Neurite outgrowth from bipolar and horizontal cells after experimental retinal detachment. Invest Ophthalmol Vis Sci 1998; 39(2): 424-34 [PMID: 9478003]

[36] Waldner DM, Giraldo Sierra NC, Bonfield S, et al. Cone dystrophy and ectopic synaptogenesis in a Cacnalf loss of function model of congenital stationary night blindness (CSNB2A). Channels (Austin) 2018; 12(1): 17-33. [Austin].

[http://dx.doi.org/10.1080/19336950.2017.1401688] [PMID: 29179637]

[37] Johnson DA, Donovan SL, Dyer MA. Mosaic deletion of Rb arrests rod differentiation and stimulates ectopic synaptogenesis in the mouse retina. J Comp Neurol 2006; 498(1): 112-28.

[http://dx.doi.org/10.1002/cne.21059] [PMID: 16856163]

[38] Michalakis S, Schäferhoff K, Spiwoks-Becker I, et al. Characterization of neurite outgrowth and ectopic synaptogenesis in response to photoreceptor dysfunction. Cell Mol Life Sci 2013; 70(10): 1831-47. [http://dx.doi.org/10.1007/s00018-012-1230-z] [PMID: 23269435]

[39] Hsu Y, Garrison JE, Seo S, Sheffield VC. The absence of BBSome function decreases synaptogenesis and causes ectopic synapse formation in the retina. Sci Rep 2020; 10(1): 8321. [http://dx.doi.org/10.1038/s41598-020-65233-4] [PMID: 32433491]

[40] Haverkamp S, Michalakis S, Claes E, et al. Synaptic plasticity in CNGA3(-/-) mice: Cone bipolar cells react on the missing cone input and form ectopic synapses with rods. J Neurosci 2006; 26(19): 5248-55.

[http://dx.doi.org/10.1523/JNEUROSCI.4483-05.2006]

[PMID: 16687517]

[41] Lorach H, Kang S, Bhuckory MB, et al. Transplantation of mature photoreceptors in rodents with retinal degeneration. Transl Vis Sci Technol 2019; 8(3): 30.

[http://dx.doi.org/10.1167/tvst.8.3.30] [PMID: 31171997]

\section{(C) 2021 Da Mota et al.}

This is an open access article distributed under the terms of the Creative Commons Attribution 4.0 International Public License (CC-BY 4.0), a copy of which is available at: https://creativecommons.org/licenses/by/4.0/legalcode. This license permits unrestricted use, distribution, and reproduction in any medium, provided the original author and source are credited. 